\title{
Are Japanese Willing to Employ a Chinese Candidate with High Language Proficiency? An Experimental Study of Prejudice in Hiring Decisions
}

\author{
Seiji Takaku ${ }^{1}$, Kuniko Takeda ${ }^{1}$, Nobuko Asai $^{2} \&$ Nobuhiko Goto $^{3}$ \\ ${ }^{1}$ Division of Social and Behavioral Sciences, Soka University of America, Aliso Viejo, USA \\ ${ }^{2}$ Faculty of Social Relations, Kyoto-Bunkyo University, Kyoto, Japan \\ ${ }^{3}$ Department of Psychology, Nagoya University, Aichi, Japan \\ Correspondence: Seiji Takaku, Division of Social and Behavioral Sciences, Soka University of America, Aliso \\ Viejo, CA92656, USA. Tel: 1-949-480-4058. E-mail: stakaku@soka.edu
}

Received: June 7, $2012 \quad$ Accepted: August 2, $2012 \quad$ Online Published: August 22, 2012

doi:10.5539/ijps.v4n3p83 URL: http://dx.doi.org/10.5539/ijps.v4n3p83

\begin{abstract}
We investigated the extent to which Japanese hold prejudice attitudes toward Chinese. Japanese participants evaluated the personality and job qualifications of a male job candidate as a function of the candidate's nationality (Japanese, Chinese, or simply Asian), the number of languages he speaks, and the level of the participants' patriotism. The Japanese participants' evaluation of the candidate was not influenced by the candidate's nationality, but was influenced by the number of languages he speaks. The level of the participants' patriotism also influenced their evaluation of the job candidate in expected and unexpected directions. Various implications of the results were discussed.
\end{abstract}

Keywords: prejudice, hiring decision, Japan-China relation, language proficiency

\section{Introduction}

Although overt discrimination against Chinese people is rare (e.g., Yang, Power, Takaku, \& Posas, 2004), Japanese sentiments toward Chinese have become increasingly negative in recent years, in part owing to China's growing economic and political influences in the world (Nakamura, 2008; Qiu, 2006). For example, Nakamura (2008) reported that Japanese sentiments toward Chinese hit the lowest level since the government started the survey in 1978. Another national survey conducted by the Ministry of Foreign Affairs of Japan in 2006 also showed that 66.7 percent of the respondents reported that Japan-China relation is "not good"; and the 2002 Yomiuri Shinbun newspaper survey also reported that 55 percent of Japanese respondents thought the Chinese people were unreliable (Qiu, 2006).

In light of these survey reports, many fear that such negative sentiments held by Japanese could easily turn into overt discrimination against Chinese. In fact, there has been an increase in more blatant discrimination against Chinese in recent year as exemplified by a group of Japanese nationalists throwing smoke bombs at the Chinese consulates in the cities of Fukuoka and Nagasaki and organizing a motorcade of several dozen cars to intimidate a bus carrying Chinese tourists in Fukuoka, which prompted Beijing to issue a warning to its citizens about the dangers of visiting Japan (MacKinnon, 2010).To prevent this type of conflicts, it is imperative to explore various ways by which such negative prejudice held by, and discrimination exercised by, Japanese against Chinese could be reduced. Thus, in this study, we attempted to address this very issue by utilizing Allport's (1954) social contact theory and Tajfel and Turner's (1979) social identity theory. Specifically, we examined whether a Chinese person's ability to speak Japanese has any effect on reducing his likelihood of getting discriminated against by Japanese who hold differing levels of patriotic attitude in a job hiring setting.

\subsection{Social Psychological Theories on Reducing Prejudice and Discrimination}

By far the most influential prejudice reduction theory is Allport's (1954) social contact theory that clarifies four essential conditions for optimal intergroup relationships: (1) equal status between the groups in the situation; (2) common goals; (3) intergroup cooperation; and (4) the support of authorities, law, or custom (Pettigrew \&Tropp, 2006). The theory has been tested and supported by past research that examined a variety of issues dealing with 
inter-group relations (see Davies, Tropp, Aron, Pettigrew, \& Wright, 2011; Pettigrew, 1998; Pettigrew \&Tropp, 2006). These studies have consistently shown that an application of the theory helps build positive inter-group relationships (e.g., Anderson, 1995; Binder et al., 2009; Desforges, Lord, Ramsey, Mason, Van, \& West, 1991; Drew, 1988; Haddock, Zanna, \& Essess, 1993).

In addition to the four conditions above, Pettigrew (1998) argued that "friendship potential" (p. 76) is a fifth, and the most essential, component that ensures the most optimal intergroup relation. He stated that the cross-group contact situations must provide participants with the opportunity to become friends, requiring extensive and repeated intergroup contacts as exemplified by the famous Robbers Cave study by Sherif and his colleagues (1961).

\subsection{Language Proficiency as an Important Factor in Increasing Friendship Potential}

Researchers who advocate the importance of friendship potential in reducing prejudice assume that people who are involved in cross-group contact situations can communicate with one another in the same language. However, in many cross-group contact situations, such an assumption is not warranted. In fact, not only having a common language is crucial to optimal intergroup relationships (e.g., Blokland, 2003; Wagner \& Machleit, 1986), whether or not one could speak the common language well plays an important role in actualizing friendship potential. This is especially true for minority group members who recently immigrated to a new country. Recent research on discrimination experienced by adolescent children of immigrants in the United States, for example, indicates that those adolescents who could not speak English well (or speak with an accent) were significantly more likely to perceive that they have been stereotyped as perpetual foreigners and been discriminated against by their majority group peers than those adolescents who could speak English well (Kim, Wang, Deng, Alvarez, \& Li, 2011; Medvedeva, 2010).

In fact, other studies (e.g., Davila \& Mora, 2004; Dustman \& Fabbri, 2003) found that immigrants with high language proficiency may experience less prejudice and discrimination because they are more likely to be employed and obtain higher earnings than those with limited language proficiency. For example, Leslie and Lindley (2001) who studied various immigrant groups in the UK found that the immigrants with high language proficiency were more likely to receive full-time education and earn higher incomes than those with limited language proficiency, and because these factors help them establish higher status in society, they are less likely to experience prejudice and discrimination.

These research findings seem to reinforce the idea that, not just having a common language, but for the minority group members, having high proficiency in the majority group's language plays a crucial role in helping members of both groups to perceive themselves as part of the same group (i.e., recategorization process), which eventually helps them actualize friendship potential and establish most optimal intergroup contact (Gaertener et al., 2000; Wright, Aron, McLaughlin-Volpe, \& Roop, 1997).

Nevertheless, because many of these studies were based on correlational method, it is difficult to isolate the causal effect of language proficiency of out-group members on reducing their likelihood of getting discriminated against by the majority group members. Thus, it is imperative to conduct a highly controlled experiment to explicate the language proficiency effect on the reduction of prejudice and discrimination.

\subsection{Present Study}

The objectives of the present study are: (1) to document experimentally to what extent contemporary Japanese express negative attitudes towards and discriminate against contemporary Chinese in a job hiring process; and (2) to assess whether manipulation of language proficiency reduces negative attitudes toward and discrimination against the Chinese candidate. Specifically, the present study followed Fein and Spencer's (1997) experimental procedure and asked the participants to evaluate the personality and job qualifications of a male job candidate, ultimately deciding on whether the candidate should be hired based on the candidate's nationality (i.e., Japanese, Chinese, or no nationality identified and simply labeled "Asian" for the control condition) and the number of languages he could speak.

Based on the literature reviewed above, the following hypotheses were proposed:

Hypothesis $1 \mathrm{a} \& 1 \mathrm{~b}$ : When the job candidate is portrayed as bilingual, the Japanese candidate (who speaks Japanese and English) is (a) perceived as possessing more positive personality and fewer negative personality traits and (b) endorsed significantly more for the position than the bilingual Chinese candidate (who speaks Chinese and English) or the bilingual Asian (control) candidate.

Hypothesis $2 \mathrm{a} \& 2 \mathrm{~b}$ : However, when the job candidate is portrayed as trilingual, (a) the difference in perceived personality traits and (b) the difference in the degree of endorsement for the position between the Japanese 
candidate and the Chinese (or the control Asian) candidate will disappear because the Chinese candidate who speaks Japanese in addition to Chinese and English is now perceived as an in-group member.

In addition to the above hypotheses, we also examined the possibility that the strength of national identity may moderate the effect of language proficiency. Social identity perspectives posit that people are motivated to achieve their distinct self-image from their social identity, and this tendency is stronger among those who strongly identify with their group (i.e., high identifiers) rather than weakly (i.e., low identifiers) (Tajfel \& Turner, 1986). For example, Jetten, Spears, and Manstead (2001) found that high identifiers showed stronger ingroup bias than low identifiers. Crisp, Stone, and Hall (2006) also found the similar results. Accordingly, we postulate the following hypothesis.

Hypothesis 3: Compared to those who are low on their level of patriotism, Japanese participants who are high on their level of patriotism are (a) less likely to infer positive personality traits of the Chinese candidate, (2) more likely to infer negative personality traits of the Chinese candidate, and (3) less likely to endorse the Chinese candidate for the position regardless of whether he speaks Japanese or not.

\section{Method}

\subsection{Participants}

A total of 312 Japanese participants were recruited at Tohoku University and NagoyaUniversity in Japan and Soka University of America in the United States, consisting of 154 males and 154 females (four participant did not provide his/her gender information). The participants' age ranged from 18 to 41 with the mean age of 20 . All participants were enrolled into a raffle to receive a \$200 visa gift card.

\subsection{Design}

The participants were asked to evaluate the personality and job qualifications of a male job candidate who is applying for an imaginary IT company in the United States and ultimately decide whether he should be hired for the position. The first independent variable (IV) was the nationality of the candidate, including Japanese, Chinese, or not mentioned (i.e., the control candidate who is simply perceived as an Asian male). The second IV was the number of languages spoken by the candidate. Specifically, the Japanese candidate was portrayed as either being able to speak two languages (i.e., Japanese and English) or three languages (i.e., Japanese, English, and Chinese); for the Chinese candidate, he was portrayed as either being able to speak two languages (i.e., Chinese and English) or three languages (i.e., Chinese, English, and Japanese); and for the control candidate, he was portrayed simply as bilingual or trilingual without specifying what languages. This IV was intended to allow the Chinese candidate to be perceived either as an "out-group" member or an "in-group" member. Thus, the study employed a 2 (the number of languages spoken) x 3 (nationality: Japanese, Chinese, or control) between-participants factorial design. Participants were randomly assigned to evaluate one of the six candidates (see Procedure section for details).

The dependent variables (DVs) were measured by a survey questionnaire issued to each participant following their thorough analysis of the job description (Appendix A), the candidate's résumé (Appendix B), and a video clip of the corresponding job interview (Appendix C). The level of prejudice was measured in two ways: (1) by the participants' evaluation of perceived personality traits of a job candidate and (2) by how much they endorsed the candidate for the position. The personality traits included nine positive traits - i.e., intelligent, trustworthy, sincere, friendly, down-to earth, creative, motivated, ambitious, and happy - and nine negative personality traits - i.e., insensitive, arrogant, inconsiderate, self-centered, rude, materialistic, conceited, vain, and superficial. The participants were asked to evaluate those traits based on a 7-point likert scale $(1=$ not at all; $7=$ very much). In addition, four questions were asked to measure participants' endorsement of the candidate for the position he was applying. The first three questions asked them how much they would agree with the following statements using a 7-point scale ( 1 = not at al; 7 = very much): (1) "I feel this person would make an excellent candidate for the position in question"; (2) "I would likely give this person serious consideration for the position in question"; (3) "I felt favorably toward this person"; and the last item by asking to fill out the blank in the following sentence: (4) "I would guess that this person is in the top__ of people interviewed."

Furthermore, the following three questions were asked to assess the degree of patriotism possessed by the participants using a 7 -point scale $(1=$ not at all; $7=$ very much): To what extent do you agree with the following statement? (1) "I love Japan"; (2) "Japan is superior to other Asian countries in many aspects"; and (3) "I am proud to be Japanese." Then, the following question was asked to assess their degree of superordinate identity based on a 7-point scale $(1=$ not at all; $7=$ very much): To what extent do you agree with the following statement? "I like being called 'Asian'." Finally, the participants were asked to write down the candidate's 
nationality, the number of languages he could speak, and his full name to ensure the success of the manipulations.

\subsection{Procedure}

An online learning management system called "Angel" was used to post the six online surveys. Furthermore, by entering the six survey links into the "url rotator," one of the six survey links was randomly sent to the participants when they agreed to participate in the survey by clicking the link provided in the invitation email sent by one of the experimenters. After consenting to take the survey, all participants were provided with general information about the research that investigates the cross-cultural differences on how people evaluate a job candidate's competence during an imaginary IT company's job interview. The participants were then shown the detailed description of the job, explaining general tasks and required skills. Then, they were shown a three-minute video presented as an excerpt from the candidate's job interview (Note 1). In the video clip, the candidate's responses to the interviewer's questions were sufficient and not overly positive or negative to provide a neutral impression. After the video, the participants reviewed the candidate's résumé, which included details about the number of languages he could speak, character-strengths, work experience, educational background, work-relevant skills, and other information that one usually finds in a professional résumé. Subsequently, the participants were asked to indicate the name of the candidate and how many and what languages the candidate is able to speak (i.e., manipulation-check questions), assess the candidate's perceived personality traits, and evaluate how much they endorse the candidate for the position. Furthermore, embedded in these questions were three questions intended to assess how patriotic these Japanese participants were and one question designed to assess the degree of their superordinate "Asian" identity.

\subsubsection{Manipulation of Candidate's Nationality}

To manipulate the candidate's national background, the following information was altered: (1) name (Wang-Xi Feng for Chinese condition, Nobuo Yoshikawa for Japanese condition, and James Francis Duran for Asian control condition), (2) language (the number and type of languages spoken), and (3) his relevant work experience (a waiter at a Chinese restaurant, Japanese restaurant, or just a restaurant). Also, the Asian actor hired to act as the candidate during the interview was chosen because he could be easily recognized as either Chinese or Japanese descent.

\subsubsection{Manipulation of Candidate's Spoken Languages}

The number and the type of languages that the candidate is able to speak were indicated in the résumé and in the job interview video clip. In the video clip, he further specified his home country (i.e., China, Japan, or unidentified) and that he had an internship experience in the respective country to impress the employer/interviewer with his language skills (i.e., interned in China for the Chinese bilingual candidate, in Japan for the Chinese trilingual candidate, Japan for the Japanese bilingual candidate, China for the Japanese trilingual candidate, and no country was specified for the Asian control candidate).

\subsubsection{Data Collection}

The data was collected through online surveys, which were issued with the help of two colleagues at Tohoku University and Nagoya University in Japan. They were asked to send the survey link to students in their classes. The Japanese online social networking website, Mixi, was also utilized as a means to contact Japanese participants. The cover story explained that Tohoku University, in alliance with a university in America, was investigating cross-cultural difference on how people evaluate a job candidate's interpersonal skills during a pseudo job interview.

Upon completion of the data collection, a debriefing letter was emailed to every participant who gave permission to contact them. After debriefing the participants with the true purpose of the study, the winner of the $\$ 200$ raffle (selected at random) was informed. This concluded the role of the survey participants.

\subsection{Translation of Materials}

Surveys were originally created in English. They were translated into Japanese and translated back into English by a second translator to ensure equivalence in meaning.

\section{Results}

\subsection{Manipulation Check}

Following the video job interview and the review of the résumé, the participants were asked to enter the candidate's name, nationality, and languages spoken. For the Chinese and Japanese candidate (both bilingual and trilingual), all participants were able to report accurately his name and the number and the type of languages he 
could speak, with only minor mistakes, such as the spelling of the candidate's name (e.g., Nobuo Yoshikawa $\rightarrow$ Noboru Yoshikawa). For the control candidate (both bilingual and trilingual candidates) whose language or nationality information was not specified, several participants (ten participants for the control bilingual candidate and thirteen participants for the control trilingual candidate) inaccurately inferred the candidate's nationality and/or the type of language he could speak. The results of the data analyses with or without these participants did not differ significantly so they were kept in the subsequent data analyses.

\subsection{Creating Indices}

Before creating an index for positive personality traits, the Chronbach's alpha value among the nine positive personality traits was calculated and found that the measure was fairly reliable $(\alpha=.76)$. As for the negative personality trait index the Chronbach's alpha value among the nine negative personality traits was .84 . As for the endorsement index, the Chronbach's alpha value among the four items was .85. As for the Japanese pride/patriotism index, the Chronbach's alpha value among the three items was . 72 .

\subsection{Testing Hypothesis}

To test hypotheses $1 \mathrm{a}-2 \mathrm{~b}$, a 2 x 3 analysis of variance (ANOVA) was performed on the positive personality index, negative personality index, and endorsement index.

\subsubsection{Positive Personality Index}

Although we predicted a significant interaction effect between the nationality and the language independent variables, the results indicated that there was only a significant main effect of the number of languages the candidate speaks on the level of positive personality inferred, $F(1,304)=6.74, p<.01, \eta^{2}=.022$. Specifically, the participants thought that the trilingual candidate possessed significantly more positive personality traits $(M=$ $4.60 ; S D=.74)$ than the bilingual candidate $(M=4.37 ; S D=.73)$ regardless of his nationality.

\subsubsection{Negative Personality Index}

Again, although we predicted a significant interaction effect between the nationality and the language independent variables, no significant result was found.

\subsubsection{Endorsement Index}

As predicted, there was a significant interaction effect between the nationality and the language independent variables, $F(2,306)=3.19, p<.05, \eta^{2}=.020$. However, this interaction effect was not the type of interaction effect we predicted. A series of post hoc tests using the Bonferroni alpha correction procedure revealed that the language variable influenced only the Japanese candidate's endorsement level, but not the Chinese or the control candidate's endorsement level. Specifically, when the Japanese candidate was portrayed as trilingual, he was endorsed significantly more for the position $(M=5.48 ; S D=1.04)$ than when he was portrayed as bilingual $(M$ $=4.80 ; S D=1.18$ ). In other words, the participants' level of endorsing the candidate was not influenced by his nationality as we predicted.

Next, to test hypothesis 3 , we first divided the participants into two groups of more-patriotic participants and less-patriotic participants using the median split procedure. We then conducted a 2 (high vs. low patriots) x 2 (bilingual vs. trilingual Chinese candidate) factorial ANOVA on the following three dependent variables: positive personality index, negative personality index, and endorsement index. Because no significant results were found for the negative personality index, we will only report the findings for the positive personality index and endorsement index.

\subsubsection{Positive Personality Index}

Though we expected only the patriotism main effect, we found that there was a significant interaction effect between the two independent variables, $F(1,96)=6.35, p<.01, \eta^{2}=.06$. To interpret this interaction, we conducted a series of post-hoc tests using the Bonferroni alpha correction procedure. We found that participants who are less patriotic perceived the bilingual Chinese candidate $(M=4.19 ; S D=1.11)$ to possess as much positive personality characteristics as the trilingual Chinese candidate $(M=4.35 ; S D=.79), t(54)=.63, p=\mathrm{ns}$. However, participants who are more patriotic perceived that the bilingual Chinese candidate to possess significantly more positive personality characteristics $(M=4.85 ; S D=.77)$ than the trilingual Chinese candidate $(M=4.11 ; S D=.70), t(42)=4.27, p<.01$.

\subsubsection{Endorsement Index}

Again, though we expected only the patriotism main effect, we found that there was a significant interaction effect between the two independent variables, $F(1,96)=6.35, p<.01, \eta^{2}=.08$. To interpret this interaction, we 
conducted a series of post-hoc tests using the Bonferroni alpha correction procedure. We found that participants who are less patriotic endorsed the trilingual Chinese candidate $(M=5.35 ; S D=1.19)$ slightly more than the bilingual Chinese candidate $(M=4.65 ; S D=1.54)$, even though this difference became technically non-significant after the Bonferroni alpha correction was applied, $t(54)=1.87, p=.05$. On the other hand, participants who are more patriotic endorsed the bilingual Chinese candidate significantly more $(M=5.65 ; S D$ $=.95)$ than the trilingual Chinese candidate $(M=4.95 ; S D=.89), t(42)=2.49, p<.01$.

\section{Discussion}

The main objectives of the present study were to document the degree to which the contemporary Japanese hold prejudice attitudes towards and discriminate against the contemporary Chinese and to assess whether such negative attitudes and behaviors could be reduced by a simple manipulation of language proficiency of the target person. Furthermore, we wanted to investigate these issues in a highly controlled experimental setting in which Japanese participants were asked to evaluate a job candidate whose nationality was manipulated to portray him as Japanese, Chinese, or simply Asian. Based on the literature review, we hypothesized that Japanese participants were more likely to endorse a Japanese job candidate rather than a Chinese job candidate. Also, when the job candidate was portrayed as Chinese, the Japanese participants would endorse the candidate who could speak Japanese in addition to Chinese and English significantly more than the candidate who does not speak Japanese (i.e., only Chinese and English).

Contrary to the hypotheses, we found that Japanese participants' evaluation of the job candidate was not influenced by the nationality manipulation. Specifically, the degree to which the candidate was perceived to possess positive personality traits was not influenced by the candidate's nationality, but by how many languages he could speak. The Japanese participants thought that the trilingual candidate, regardless of his nationality, possessed more positive personality traits than the bilingual candidate. Furthermore, the degree to which the candidate was perceived to possess negative personality traits was influenced neither by the candidate's nationality nor the number of languages he could speak. Finally, the degree to which the candidate was endorsed for the position was influenced both by the candidate's nationality and the languages he could speak, but not in the direction we expected. Though we expected that the Japanese participants would endorse the Chinese candidate as much as, if not more than, the Japanese candidate if he is portrayed as being able to speak Japanese and know much about the Japanese culture, we found that the Japanese participants endorsed all candidates equally regardless of the candidate's nationality or the number of languages he could speak, except for the trilingual Japanese candidate who was endorsed significantly more than the bilingual Japanese candidate. We would like discuss a few implications of these findings below.

First and foremost, the Japanese participants, or more specifically Japanese undergraduate students who participated in this study are not as prejudiced as we expected and they seemed to be able to evaluate the candidate solely based on the merit of his job relevant skills, talents, and experiences. This hopeful finding may be the result of Japanese people's conscious effort to "right the wrong" by carefully re-assessing the historical cause of China's anti-Japanese sentiments. For example, evidence for such an effort can be seen in the comment made by a Japanese reporter who reported after the rioting at the 2004 Asian Cup Soccer Games, in which the reporter stated, "People in Japan should ask themselves why such anti-Japanese behavior manifested itself, a necessary prelude to searching for ways to understand and hopefully defuse the obvious rancor exhibited in China" (as cited in Qiu, 2006, p. 29).

Secondly, one potential reason why the language manipulation only influenced the Japanese participants' evaluation of the Japanese candidate, but not the Chinese or the control candidate, may have to do with the fact that knowing Chinese is more important in today's ever globalizing world economy than knowing Japanese and that knowing English is no longer perceived as a special advantage. Thus, when the Japanese candidate was portrayed as being able to speak Chinese in addition to English (i.e., the trilingual Japanese candidate), the Japanese participants endorsed him significantly more than the bilingual Japanese candidate. However, when evaluating the Chinese candidate, the Japanese participants did not think that knowing Japanese (i.e., the trilingual Chinese candidate) would make the candidate any more advantageous than knowing the two most important languages in today's world, namely Chinese and English. Likewise, the fact that the language manipulation did not influence the Japanese participants' evaluation of the control candidate may imply that knowing what specific languages a given candidate could speak is more important than simply knowing the number of languages he could speak.

Another interesting finding from this study was that even though we predicted that the higher the Japanese participants' level of patriotism, the more they would discriminate against the Chinese candidate regardless of 
whether he speaks Japanese or not, we found no evidence for this prediction. On the contrary, we found that highly patriotic participants perceived the trilingual Chinese candidate who speaks Japanese to not only possess significantly less positive personality traits but also endorsed him significantly less than the bilingual Chinese candidate who does not speak Japanese. One potential interpretation of this rather contradictory finding is that those who were highly patriotic might have felt "threatened" by a very capable Chinese candidate who not only speak English but also Japanese and reacted toward him in a negative manner. The fact that non-patriotic participants endorsed the trilingual Chinese candidate slightly more than the bilingual Chinese candidate further supports the notion that these participants were not "threatened" by the capable Chinese trilingual candidate, recognized his talent, and thus treated him accordingly.

Although this particular research finding is intriguing and its potential explanations are many, further analyses of the data suggest that how the Japanese construct their self-identity does seem to play an important role in reducing prejudice against Chinese people. As mentioned previously, one of the questions we asked the Japanese participants was how proud they were to be considered Asian. We wanted to see if the stronger the super-ordinate identity the Japanese possess (i.e., I am an Asian), the more likely they would be to endorse the Chinese candidate. The results clearly showed that the stronger the super-ordinate identity the Japanese participants possessed, the more they thought that (1) the Chinese candidate possessed positive personality characteristics $(\beta$ $=.23, p<.01)$ and $(2)$ the more they endorsed him as a result $(\beta=.26, p<.01)$, regardless of whether he speaks Japanese or not. In addition, the same, yet much stronger, pattern of results was found when evaluating the control candidate whom the Japanese participants could only recognize him as an Asian $(\beta=.40, p<.001$ for positive personality characteristics and $\beta=.35, p<.001$ for their endorsement of the candidate, respectively). Taken together, these results strongly suggest that enhancing people's superordinate identity plays an essential part in reducing prejudice and creating a more positive relationship between the two antagonized groups.

\subsection{Limitations and Suggestions for Future Studies}

Despite the positive and promising results of the present study, we still need to address some limitations of the study. First, though we have collected a sufficient number of participants to produce enough statistical power for the type of research design used in this study, the participants were mostly college students, who are younger and more educated than the general population and, therefore, the results may not be generalizable to the entire Japanese population. However, this should not be considered only as a limitation. Though the older Japanese generation might still hold strong prejudice against the Chinese people, these young college students are the ones who will shoulder and shape their future relationship with the Chinese people. Therefore, our findings seem to bode well for the future of the two nations.

However, even then, it is still possible that the Japanese participants did not show any sign of prejudice against the Chinese candidate or show any preferential treatment for the Japanese candidate because the company to which the candidate was applying was indicated as an American company. In other words, if the company was indicated as a Japanese company, then the Japanese participants might have felt stronger urge to treat the Japanese candidate more favorably than the Chinese candidate. However, at the same time, by portraying the company as an American company (i.e., neither Japanese nor Chinese company), we believe that the entire evaluation process was made more objective.

Though this may be a minor issue, due to the nature of the online survey, there was no way for the researchers to control for the environment in which the participants took the survey. It is quite possible that some participants were distracted by others or discussed their responses to the survey with them; thereby preventing them from thoroughly examining various factors presented and/or providing their true opinions on the candidate. But, even this were the case for some participants, because of the random assignment used, such noises were equally distributed among the six conditions, making them poor candidates for confounding variables.

\subsection{Conclusion}

There is no doubt that the atrocities committed by the Japanese military during WWII have not only damaged and will continue to influence the Sino-Japan relation, they have also been shaping the attitudes that the people of the two nations hold toward each other. However, despite such historical and many current obstacles that hinder their effort towards improving their relationship, the results of the present study suggest that there is a brighter future ahead for the two nations. Specifically, as demonstrated by many past studies, our findings strongly support the idea that to reduce prejudice and discrimination, it is important for the people involved in an intergroup conflict to internalize a superordinate identity so that any negative sentiments they may hold toward one another can be reduced and the relationship between the two groups can be improved. 


\section{Acknowledgments}

This research was supported by a grant given to the first author by the Pacific Basin Research Center at Soka University of America. We would like to thank Nanci Lawson, Barbara McGrath, and Andrew Welty for their assistance in developing the online surveys for this research.

\section{References}

Allport, G. (1954). The nature of prejudice.Cambridge. MA: Addison-Wesley.

Anderson, L. S. (1995). Outdoor adventure recreation and social integration: A social-psychological perspective. Dissertation Abstracts International Section A: Humanities and Social Sciences, 55(7-A), 2137.

Binder, J., Zagefka, H., Brown, R., Funke, F., Kessler, T., Mummendey, A., Maquil, A., Demoulin, S., \& Leyens, J. (2009). Does contact reduce prejudice or does prejudice reduce contact? A longitudinal test of the contact hypothesis among majority groups in three European countries. Journal of Personality and Social Psychology, 96(4), 843-856. http://dx.doi.org/10.1037/a0013470

Blokland, T. (2003). Ethnic complexity: Routes to discriminatory repertoires in an inner-city neighbourhood. Ethnic and Racial Studies, 26(1), 1-24. http://dx.doi.org/10.1080/01419870022000025252

Crisp, R. J., Stone, C. H., \& Hall, N. R. (2006). Recategorization and subgroup identification: Predicting and preventing threats from common ingroups. Personality and Social Psychology Bulletin, 32(2), 230-243. http://dx.doi.org/10.1177/0146167205280908

Davies, K., Tropp, L. R., Aron, A., Pettigrew, T. F., \& Wright, S. C. (2011). Cross-group friendships and intergroup attitudes: A meta-analytic review. Personality and Social Psychology Review, 15, 332-351.

Davila, A., \& Mora, M., T. (2004). English-language skills and the earnings of self-employed immigrants in the United States: A note. Industrial Relations, 43(2), 386-390. http://dx.doi.org/10.1111/j.0019-8676.2004.00335.x

Desforges, D. M., Lord, C. G., Ramsey, S. L., Mason, J. A., Van, L. M., \& West, S. C. (1991). Effects of structured cooperative contact on changing negative attitudes toward stigmatized social groups. Journal of Personality and Social Psychology, 60(4), 531-554. http://dx.doi.org/10.1037/0022-3514.60.4.531

Dustmann, C., \& Fabbri, F. (2003). Proficiency and labour market performance of immigrants in the UK. The Economic Journal, 113(489), 695-717. http://dx.doi.org/10.1111/1468-0297.t01-1-00151

Drew, B. (1989). Intergenerational contact in the workplace: An anthropological study of relationships in the secondary labor market. Dissertation Abstract International, 50(4).

Fein, S., \& Spencer, S. J. (1997). Prejudice as Self-Image Maintenance: Affirming the Self through Derogating $\begin{array}{lllll}\text { Others. Journal of Personality and Social Psychology, 73(1), 31-44. } & \text {. }\end{array}$ http://dx.doi.org/10.1037/0022-3514.73.1.31

Gaertner, L. S., Dovidio, F. J., Banker, S. B., Houlette, M., Johnson, M. K., \& McGlynn, A. E. (2000). Reducing intergroup conflict: From superordinate goals to decategorization, recategorization, and mutual differentiation. The Educational Publishing Foundation, 4(1), 98-114.

Haddock, G., Zanna, M. P., \& Esses, V. M. (1993). Assessing the structure of prejudicial attitudes. The case of attitudes towards homosexuals. Journal of Personality and Social Psychology, 65, 1105-1118. http://dx.doi.org/10.1037/0022-3514.65.6.1105

Jetten, J., Spears, R., \& Manstead, A. S. R. (2001). Similarity as a source of discrimination: The role of group identification. European Journal of Social Psychology, 31, 621-640. http://dx.doi.org/10.1002/ejsp.72

Kim, S. Y., Wang, Y., Deng, S., Alvarez, R., \& Li, J. (2011). Accent, perpetual foreigner stereotype, and perceived discrimination as indirect links between English proficiency and depressive sympotoms in Chinese American adolescents. Developmental Psychology, 47, 289-301. http://dx.doi.org/10.1037/a0020712

Leslie, D. \& Lindley, J. (2001). The impact of language ability on employment and earnings of Britain's ethnic communities.Economia, New Series, 68(272), 587-606. http://dx.doi.org/10.1111/1468-0335.00263

MacKinnon, M. (2010, June 6). A black sun rises in a declining Japan. The Globe and Mail. Retrieved from http://www.theglobeandmail.com/news/world/a-black-sun-rises-in-a-declining-japan/article1215080/

Medvedeva, M. (2010). Perceived discrimination and linguistic adaptation of adolescent children of immigrants. Journal of Youth Adolescence, 39, 940-952. http://dx.doi.org/10.1007/s10964-009-9434-8 
Ministry of Foreign Affairs of Japan. (2006, February). Ministry of Foreign Affairs of Japan: Nicchukankeinikansuruishikichosa. Retrieved from http://www.mofa.go.jp/mofaj/area/CHINA/yoron05/indec.html (February 12, 2010)

Nakamura, K. (2008). Japanese's increasing and deepening hatred toward Chinese. Retrieved from http://www.21ccs.jp/china_watching/KeyNumber_NAKAMURA/Key_number_52.html

Pettigrew, F. T. (1998). Intergroup Contact Theory, Annual Review Pscychology, 49, 65-85. http://dx.doi.org/10.1146/annurev.psych.49.1.65

Pettigrew, F. T., \& Tropp, R. L. (2006). A meta-analytic test of intergroup contact theory. Journal of Personality and Social Psychology, 90(5), 751-783. http://dx.doi.org/10.1037/0022-3514.90.5.751

Qiu, J. (2006). The politics of history and historical memory in China-Japan relations. Journal of Chinese Political Science, 11(1), 25-52. http://dx.doi.org/10.1007/BF02877032

Sherif, M., Harvey, O. J., White, B. J., Hood, W. R., \& Sherif, C. W. (1961). Intergroup conflict and cooperation: The Robbers Cave experiment. Norman: University of Oklahoma Book Exchange.

Tajfel, H., \& Turner, J. (1986). The social identity theory of intergroup behavior. In S. Worchel \& W. G. Austin (Eds.), Psychology of Intergroup Relations (pp.7-24). Chicago: Nelson-Hall.

Yang, P. Q., Power, S., Takaku, S., \& Posas, L. (2004). Immigration and ethnic conflict in comparative perspective. In Y-T. Lee, C. McCauley, F. Moghaddam \& S. Worchel (Eds.), The Psychology of Ethnic and Cultural Conflict. Westport, CA: Greenwood.

Wagner, U., \& Machleit, U. (1986). "Gestarbeiter" in the Federal Republic of Germany: Contact between German and migrant populations. In M. Hewstone \& R. Brown (Eds.), Contact and Conflict in Intergroup Encounters (pp. 59 - 78). Oxford: Basil Blackwell.

Wright, C. S., Aron, A., McLaughlin-Volpe, T., \& Roop, A. S. (1997). The extended contact effect: Knowledge of cross-group friendships and prejudice. Journal of Personality and Social Psychology, 73(1), 73-90. http://dx.doi.org/10.1037/0022-3514.73.1.73

Yang, P. Q., Power, S., Takaku, S., \& Posas, L. (2004). Immigration and ethnic conflict in comparative perspective. In Y-T. Lee, C. McCauley, F. Moghaddam \& S. Worchel (Eds.), The Psychology of Ethnic and Cultural Conflict. Westport, CA: Greenwood.

\section{Note}

Note 1. The entire interview was done in English, but we provided the subtitle on the bottom of the screen so the Japanese participants were able to understand the entire conversation during the job interview.

\section{Appendix A}

Job Description

Job Description: Offering a position for technical support and training to departmental staff using computer equipment and applications on a wide area network (WAN) or large local area network (LAN); installs, tests, and resolves problems with computer hardware and software; utilizes existing software to accommodate the database needs of departments; develops and maintains Intranet and Internet Web sites, and performs related duties as required.

Distinguishing Characteristics: Computer Systems Specialist is an intermediate-level position. Incumbents learn to perform the full range of technical support duties. 


\section{Appendix B}

\section{NOBUO YOSHIKAWA}

19385 Blue Crest Ave. Huntington Beach, CA (714) xxx - 0037

nyoshikawa821@xxxxxxx

\section{OBJECTIVE:}

To obtain a position as computer systems specialist with Premiere Tech United.

\section{EDUCATION:}

I have recently graduated from California State University of Northridge with a B.S. in computer science.

\section{CONTRIBUTIVE SKILLS:}

- Clerical abilities.

- Passionate about computers and information technology.

- Great memorization skills.

- $\quad$ Ability to expand my learning potential in different circumstances.

- $\quad$ Self-motivated and committed.

- $\quad$ Dedicated to achieving my goals.

- Resourceful.

- $\quad$ Ability to exercise my creativity by generating ideas very quickly.

- Trilingual: English, Japanese, Chinese

\section{EXPERIENCE:}

Web Designer / Internet Support

Dec. 2005 - May 2007

Information Technology Department, CSUN

- $\quad$ Developed passion for technology by working increasingly closer with wide area network WAN and local area network LAN.

- $\quad$ Designed web pages for department while learning how to precisely alter and recode each, in addition to other formats.

- $\quad$ Learned .BIN, .CUE, .ISO, .BMP, .EXE, .M3U, .WMV, .APP, .MP4, .MPEG, in addition to many other file types.

\section{Student Support Specialist}

Mar. 2005 - Nov. 2005

Information Technology Department, CSUN

- $\quad$ Provided support to students campus-wide in general areas such as broken sound cards and ineffective Wi-Fi and Bluetooth modulators.

- $\quad$ Completed weekly projects fixing classroom audio / visual systems and equipment. Gave introductory computer lessons to students.

\section{Restaurant Waiter}

Oct. $2002-$ Aug. 2004

Jade Palace Restaurant

- Constantly worked with customers in order to build positive relationships.

- $\quad$ Developed personality skills to improve friendliness while maintaining a great work ethic. 


\section{Appendix C}

Interviewer: "Hi. How are you doing? Please take a seat. My name is Andrew and I am the department manager here at the Premier Tech United."

Candidate: "Thank you. Here is a copy of my resume."

Interviewer: "Alright, thank you. Ok, let's get started. Mr. Yoshikawa / Mr. Wang / Mr. Duran, why don't you introduce yourself first?"

Candidate: "Hello, my name is Nobuo Yoshikawa / Wang-Xi Feng / James Francis Duran. I am 24 years old. I was born in Tokyo, Japan / Beijing, China / Not mentioned. When I was 15 years old, I moved to the United States to learn English. After graduating from high school I attended California State University, Northridge, where I earned my Bachelor's degree in computer science. I also spent two summers interning at a Chinese (Japanese/not mentioned) technology development company in Beijing, China (for trilingual Japanese) / Tokyo, Japan (for trilingual Chinese) / not mentioned (for trilingual control) while I was at Cal State Northridge."

Interviewer: "Oh, great. So, you speak two languages, is that right?"

Candidate: "As a matter of fact, I speak three languages."

Interviewer: "Oh, really, so aside from Japanese and English, what else do you speak?"

Candidate: "I also speak Chinese."

Interviewer: "Where did that come from?"

Candidate: "Well, as part of our curriculum at Cal State Northridge, I had an opportunity to study abroad in Beijing, China.

Interviewer: "OK, great."

Interviewer: "I noticed that you are 24 years old. So, what did you do after you graduated?"

Candidate: "Actually, after graduating from college, I had planned to start my career, but my family had some problems so I had to return home to support them. But now, those issues have been resolved, so I wanted to return to the United States in search of a career."

Interviewer: "Alright. As you may know, there are many candidates applying for this job. What makes you more qualified for this job?"

Candidate: "Well, to start off, I have studied three years of technology development and wireless communications in college. Also, as I mentioned before, I interned for two summers at an information technology company. And, during my internship, I was able to develop practical skills in the field of computer technology, applied them directly to my work."

Interviewer: "Alright, sounds like you have the experiences that are necessary for this position. So if hired, how much time would you be willing to commit to this position?"

Candidate: "Well, I am looking for a full time job, so 40 or more hours a week."

Interviewer: "Alright. As you might have read in the job description, this position requires a lot of patience and willingness to sit in front of a desk organizing files, updating software, and repairing anything that may have problems. How do you feel about this?"

Candidate: "Well, I am a very goal-oriented person. My tasks are my first priority. I do not lose focus easily, and I am confident in my ability to concentrate on what needs to be done."

Interviewer: "Well, you sound like you are a solid candidate for us. Ok, that pretty much wraps it up for us. Are there any questions that you may have for us?"

Candidate: "When should I be hearing back from you?"

Interviewer: "A good question. Our secretary should be contacting you in the next two to three weeks." 